\title{
The Need to Foster Creativity and Digital Inclusion among Women Users in Developing Context - Addressing Second Order Digital Divide in Online Skills
}

\author{
http://dx.doi.org/10.3991/ijet.v10i3.4248 \\ Chunfang Zhou, Aparna Purushothaman \\ Aalborg University, Aalborg, Denmark
}

\begin{abstract}
This paper provides a literature review aiming to discuss the need for fostering creativity and digital inclusion among women students in developing contexts by addressing the second order digital divide in online skills. As the literature review indicates, we are in the change towards creative society and creativity is the core competency of students to be mastered in the digital age. The digital technologies also provide conditions of developing creativity, for example, YouTube can be regarded as a creative platform. This paper also discusses the links between creativity, learning and knowledge, digital divide in developing contexts especially the second order digital divide as the main barrier to women students' learning. This further implies how to teach creativity more effectively in the future.
\end{abstract}

Index Terms-Second-order Digital Divide; Online Skills; Creativity; Gender

\section{INTRODUCTION}

Internet is one of the Information and Communication Technologies (ICTs) that brought massive change in the ways people communicate and how information is exchanged across the globe. Through Internet wide range of information is available, free of cost which has unthinkable 20 years ago, which facilitates sharing of large scale information through websites, virtual classrooms, virtual libraries and through emails [1]. Internet has become a platform for engagement in a variety of activities which substitute for parallel activities in the physical, face-toface world [2]. In the twenty first century the educational and economic development of a society will depend on citizens attitudes towards using and learning the internet [3].

The rapid development of Internet technologies has called for a growing engagement with a 'making and doing' culture for creativity. This orientation rejects the passivity of learning, and seeks opportunities for creativity, social connections, and personal growth. It means some teachers are beginning to reject the 'sit back and be told' school culture and instead are setting their students challenges which are much more about making and doing. Students are encouraged to work together to ask questions, explore different strategies of investigation, and create their own solutions. This approach is open about the fact that learning is an ongoing process that everyone is engaged in - teachers themselves might show that they are engaged in a learning project, such as staring to keep bees, or learning a musical instrument. Rather than displaying laminated examples of the 'best answer' on the walls, these classrooms show work in progress, experiments, even things that have gone wring. They encourage a 'hands-on' approach to learning, and a spirit of enquiry and questioning [4].

However, the digital divide exists in developing context that is the one of barriers to learning Internet skills, especially among woman users. This further causes the inequality of developing creativity and digital inclusion between men and women. Such considerations lead this paper to address the second order digital divide in online skills that aims to underpin the need to foster creativity and digital inclusion among women users in developing contexts. Thus, this paper will start with definition of creativity in digital age that is followed by an example of regarding YouTube as a creative platform and the links between creativity, knowledge and learning. It then will turn to discussions on digital divide and the second order digital divide in developing contexts. This will finally lead to implications for how to teach creativity more effectively among women users of Internet in developing contexts.

\section{Defining CReatVitTy In Digital Age}

Since the end of 1990 s, creativity has become a growing area of interest within education, as well as within society as a whole. It reflects the globalization of economic activity, which has led to increased competition for markets [5]. It has been considered as a key capability that future citizens should master due to the increasing challenges of workplace in current digital age.

Although there are diverse expressions of the definition, creativity is usually thought as involving the generation of novel and useful ideas [6]. The field of creativity was practically somnolent when Guilford [7] woke it up more than half-a-century ago with a presidential address to the American Psychological Association [8]. Today the field has seen an explosion of interest. As the Handbook of Creativity [9] indicates, the development of scientific thinking about creativity has followed a particular trajectory: going from an early emphasis upon isolated individuals and their internal traits and capabilities, followed by a developing a focus on the interaction between individuals and the environment.

One popular way of defining creativity is from the system view. Csikszentmihalyi [10] argued that creativity results from the interaction of a system composed of three 
elements: a culture hat contains symbolic rules, a person who brings novelty into the symbolic domain, and a field of experts who recognize and validate the innovation. So creativity is a process by which a symbolic domain in the culture is changed. New songs, new ideas, new machines are what creativity is all about [4].

By considering the roles of technologies such as Internet in creativity development in current digital age, Gauntlett [4] argued that there are three principles ways of understanding the culture of 'making is connecting':

1. Making is connecting because you have to connect things together (materials, ideas, or both) to make something new;

2. Making is connecting because acts of creativity usually involve, at some point, a social dimension and connect use with other people;

3. And making is connecting because through making things and sharing them in the world, we increase our engagement and connection with our social and physical environments.

Although the word 'making is connecting' is perfectly simple phrase, it is meaningful and pleasing to consider the links between creativity, technology and digital skills, and to consider 'making', 'connecting' and 'creating' are same processes in particular to the context of using Internet. And the power of making, and connecting through creating, extends well beyond the online world to all kinds of activities in everyday life. For example Web 2.0, as an approach to the Web, is about harnessing the collective abilities of the members of an online network, to make an especially powerful resource or service. But, thinking beyond the Web, it may also be valuable to consider Web 2.0 as a metaphor, for any collective activity which is enabled by people's passions and becomes something greater than the sum of its parts [4].

\section{YouTube as a CReative Platform}

As mentioned previously, Web 2.0 applications that encourage people to make and share things are often not very specific tools, as such, but are broad platforms. The word 'platform' is a right common-sense word to describe the kind of stage that they offer to creative performance. They encourage users to express their creativity in whatever way they choose - within a particular framework, and general type of content. YouTube is now one of most well-established of these platforms [4].

Unlike a blog, for instance, which can be immediately contributed to by typing on a keyboard and hitting 'publish', production of a watchable YouTube video usually requires at least a little more work-most often recording using a digital video camera, followed by some editing before the work can be uploaded. Another alternative is to use screen-capture software to make a video recording of a PowerPoint presentation with an audio commentary. According to Gauntlett [4], YouTube is an archetypal digital creative platform in three key ways.

\section{A. A framework for participation}

This highlights the sense in which YouTube is essentially 'just' a platform for creativity. In an unglamorous formulation, it is a database website, which invites people to add data as files, comments, tags, and links between different bits of information. One view of such a platform is that it is a (commercial) service offered to users who know what they are dealing with when they use it, and who are basically pleased that it gives them a stage on which to share their thoughts and their creative work, and a network through which they can connect with others, for free.

\section{B. Agnostic about content}

YouTube is entirely agnostic about what contributions can be made (apart from some precautions about pornographic and potentially offensive or abusive material). The platform is presented, but the opportunities for innovation in content are left open to the users. Some people have used it in ways that mimic established forms of styles, such as the music video, the interview, the comedy sketch, or the product review 'show'. A number of these individuals aspired to enter the mainstream media, and some have done so when their YouTube popularity has brought them to the attention of the traditional industry.

\section{Fostering community}

YouTube is more than a video archive: it is, and keenly positions itself as, a community. YouTube actively encourages users to make comments, to subscribe, to give star ratings, to add friends and send messages, and to make videos responding to other videos. People use YouTube to communicate and connect, to share knowledge and skills, and to entertain. They use the community features of the site to support each other and engage in debates, and to generate now creative power in collaboration.

However, it is true that the majority of visitors to YouTube are viewing, not producing and participating, there are still literally millions of users who engage with creative platform very day, and whose relationship with professional media has been fundamentally shifted because of the knowledge that they can be creators, and not just receivers, of inventive media [4].

\section{CREATING, KNOWLEDGE AND LEARNING}

Undoubtedly, learning is a process or activity of achieving new knowledge, experience or ability. Learning is also regarded as competence development and meanwhile it is related to creativity. However, creativity and knowledge are not opposed to each other, even though an overemphasis on current knowledge can sometimes smother creativity. On the contrary, creative thinking cannot happen unless the thinker already possesses knowledge of a certain reach and/or of a well-structured kind. However, the earlier studies on relationships between creativity and knowledge were discussed from cognitive or psychological perspectives [10]. For example, Amabile [11] summarizes her views on creativity in the context of a discussion of how to increase the chance of raising children who can think creatively. She presents the following as some the thinking styles that are often observed in creative adults and children: (1) breaking set, that is breaking out of your old patterns of thinking about something; (2) breaking out of scripts, which is much the same thing; and (3) perceiving freshly, that is, changing one's old ways [12].

Recent studies on creativity development in group or collaboration contexts have focused more on regarding individuals as a potential resource for group products than on considering individual cognitive processes. As Nijstad 
and Paulus [13] emphasized, the knowledge of a collection of individuals is, in principle, larger than the knowledge of one individual, and the set of skills and abilities possessed by the group is larger than the set of skills and abilities possessed by an individual group member. One could therefore argue that groups have creative potential-because individual knowledge, skills, and abilities are combined, the group has the potential to be more creative than its separate members. However, a groups' creative potential also depends on the level of diversity. Collaborators are not homogeneous people, but rather individuals with different perspectives, experiences, expertise, conceptualizations, working methods, temperaments, resources, needs, and talents. The interaction of these differences forms the foundation which enables the dynamic of collaboration to unfold [14]. In addition, tacit knowledge in process of group innovation has been emphasized. Leonard and Sensiper [15] pointed out that one form of collective tacit knowledge encompasses the entire production system, allowing individuals to contribute to innovation without explicit communication because they understand at a systemic level how all the individual operations in an organization fit together [12] .

However, any new idea can be a potential start for learning new knowledge. Thus, creativity is an inspirational force that generates new ideas or produces novel combinations of existing ideas, leading to further solutions or a deeper understanding [15]. As Craft [16] emphasizes, we can see creativity as offering students opportunities to shape new knowledge. In this sense, group creativity could be viewed as a driver of the spiral of knowledge creation models. In other words, knowledge creation does not start from scratch but is a process of transforming and developing - sometimes in a radical way-existing ideas and practices [16]. Creative ideas motivate and direct the transforming process, since any learning activities seek the pursuit of newness. Creative expertise is the continuous effort of going beyond the current level of accomplishment and working at the edge of one's competence to adapt to the progressively changing requirements of the environment [17]. So in groups or collaborative processes, creativity and learning are closely related. It is impossible to distinguish between the processes of participation, interaction and response, and creative activity and learning [18].

Accordingly, the ICTs have accentuated the need for creative thinking in all aspects of our lives, and have also provided tools that can help us improve and reinvent ourselves. ICT makes possible asynchronous learning, or learning characterized by a time lag between the delivery of instruction and its reception by learners. The educators must make sure that students' creativity is nourished and developed. To achieve this goal will require us a deep understanding about the relationships between creativity, knowledge and roles of ICT in learning [19]. However, the digital divide is one of the barriers to creativity in developing context, especially for women users of Internet.

\section{CREATIVE Society AND Digital DiVIDE IN DEVELOPING CONTEXT}

The combined processing and networking power of ICTs has led to a global socio-economic paradigm shift which other earlier technologies like radio and television could not bring [20]. Throughout the 1980s and 1990s, a technological revolution has occurred, firstly through the large scale use of adoption of computers and then in the form of ongoing Internet revolution which had an exponential growth rate making it's a prerequisite for the information age [21]. We began to realize that information itself would not only bring about important change, but also the key was how people transformed information into knowledge and managed that knowledge. The shift in focus from "information" to "knowledge" is an improvement that leads to a conception of "Creative Society" formulated. This conception means in the future, success will be based not on how much we know, but on our ability to think and act creatively [18].

As the computers were the cutting edge technology in 1980s, where personal computers and computer networks began to take over offices and became widely popular [2223], the Internet represents cutting edge technology in the 1990 s with the introduction of first browsers and the emergence and wide spread acceptance of Microsoft Windows and Apple systems with advanced graphic solutions [22-23]. Few technologies had such a global impact cutting across wide range of sectors and within diverse socioeconomic groups like the internet based technologies and world wide web, which are expanding at an exponential rate [24]. Amichai-Hamburger [25] argues that Internet is a way to complete the daily task, to gather information and is also a source of entertainment and touches upon every aspect of our life. Nwagwu et al. [26] describe Internet as an "unsurpassed repository of information of all kinds - from specific to general, from minutiae to trivia to depth of detail, to historic and up-to-the minute". Even though information is abundant in the Internet, what is challenging is how to use the available information as; unlike much other information.

Even though the growth of ICT has been exponential, it has not been evenly distributed within societies or around the world, which makes people from these countries, not able to take advantage of ICT, as they do not have access to it [20]. As any other new technology, the Internet has been unequally distributed across societies and therefore does not offer the same opportunities to everyone or every social group to the same extent [27-28]. While in most developed countries it is difficult to imagine day-to-day life without Internet, two-thirds of the world's population, and more than three quarters of the population in developing countries, are not yet online, and of those that are, many do not have access to high-speed, high-quality Internet services $[29$, p. 8$]$. Only $31 \%$ of the population use the Internet compared to $77 \%$ in the developed world according to the ITU [30]. Some scholars add the social dimension to describe the digital divide. Warschauer [31] elucidate that, the concept of a 'digital divide' needs to be conceptualized in a different angle where technology access has to be analyzed in terms of social inclusion to encompass the wide range of factors such as physical, digital, human and social factors. For example, there is serious inequality of resource between university and school levels education. In level of higher education we have good infrastructure; every student can access to the Internet and institutes, they are active to use ICT for teaching activities. Thai government started to build up backbone connection for education since 2002 as called "UniNET". However in school level, a number of schools where locate in rural area, they do not have Internet connection but they have mobile. Mostly they are primary 
school and very few numbers of high schools that do not have connection [32].

\section{SECOND ORDER DIVIDE IN ONLINE SKILLS AND GENDER DIFFERENCES IN LEARNING TECHNOLOGIES}

Internet or digital skills are not equally distributed in the society [33-34]. The lack of skills to use the Internet is a major factor that contributes to second-order divide [35]. What is seen is that even though the physical access gap is addressed and closed in developing countries the skills gap tends to grow [36]. Having the requisite skills to retrieve and use the information from the Internet also influences an individuals Internet self-efficacy. "Internet self efficacy is a user's perception about his/her own ability in using the Internet" [37, p. 48]. The authors would like to argue that as ones ability to use retrieve and find the information increases so does the Internet self-efficacy. Having the skills to use the Internet is also related to their women users motivation to use the Internet in future. If the women end up frustrated when using the Internet, they may not be motivated to use the Internet in future.

Lack of skills and knowledge is a major hindrance for women's use of computers and ICT in developing context [38]. This is also extended to using Internet. In a recent study done on women users who were master's students in a university in a developing context it was found that lack of online skills to make use of the available Internet access became a barrier for being a participant in the information age [39]. The skills to use the Internet can reduce the women users technophobia in using the Internet. Technophobia as regards Internet usage could be because of lack of skills. Women generally are found to show anxiety as regards Internet usage which brings technophobia in them [39]. This could be also because of the lack of skills to know how to retrieve and use the Information. For example, since the early $1950 \mathrm{~s}$, India have identified the need to use all modes of media for promoting development and, implicitly, for education. However, availability and affordability are the determining factors for technology adoption in education in India. The main challenges which the country face in the successful use of ICT in the educational sector are deficit power supply, lack of adequate physical facilities, high cost of connectivity, bad maintenance of infrastructural facilities, lack of trained teachers, no proper focus on the digital content in education, not much attention given to the local language content development and deployment [32].

Meanwhile, recent studies on self-assessments on gender differences showed the females tend to attribute the causes of differences to themselves. Few of women thought the causes were from external environment [40]. Thus the females are self-contemptuous seriously in general. Felder et al. [41] found that in engineering education context, the boys always expressed higher selfassessments on their abilities of solving basic problems, creative problems and computer problems than girls. For those who were more closing to graduation, their abilities to solve problem creatively were better. Compared with boys, girls tended more to attribute poor performance to lack of abilities and thought their success as help from outside. However, when boys failed in doing something, they tended to think it was due to lack of hard work or being treated unfairly. In addition, boys always regarded success as their abilities. In terms of why the females tend to alienate the computer programming, Weisman [42] provided some evidence from physiological perspective. In his study, he found the females preferred to touch those natural materials that may appease and stimulate the senses when they were asked to paint their ideal housing environment in the workshops. It is therefore no surprising that the males dominate the computer fields, since the females are not as interested in frigid artifacts as males. A similar study also has been done by Raat and Marc [43]. It was found that understandings of conceptions related to technology were ambiguous for the children at 13 years old or so; the girls' interests in technology and their assessments on the importance of technology were much worse than boys.

\section{IMPLICATIONS: HOW TO TEACH CREATIVITY MORE EFFECTIVELY AMONG WOMEN USERS?}

Broadly, in the culture shift towards 'making is connecting', Gauntlett [4] describes the future scenario for education. In the new system, students work on learning projects, in which their teachers encourage them to ask questions and to seek out understanding for themselves. To present their learning to others, they produce exhibitions, physical performances, online presentations, and games. They are inspired by their teachers, who are no longer just the holders of the 'answer book' but are visibly also learning knowledge and skills in their own lives. Accordingly, Zhou [44] figured out a series of potential educational strategies of teaching creativity including improving conceptualization of creativity among students, stimulating motivation of both learning and teaching creativity, using group wok, organizing learning activities by student projects, and practicing 'student-centered learning', and so on. Such strategies also make sense among women students.

Moreover, in terms of dealing with the digital divide, one of the greatest challenges in ICT use in education is balancing educational goals with economic realities in developing contexts. ICTs in education programs require large capital investments and developing countries need to be prudent in making decisions about what models of the ICT use will be introduced and to be conscious of maintaining economies of scale. The potential sources of money and resources for the ICTs use programme can include private donations, community support, membership fees, and public subsidies, etc. Multilateral organizations and international aid agencies have also potential to drive the ICTs in education efforts in the developing world. For example, the Coca-Cola Company's ICT in Education partnerships with governments, multilateral organizations, non-governmental organizations and educators in the Asia Pacific began in 1997 with establishment of the first CocaCola Learning Center in Ho Chi Minh City, Vietnam. Coca-Cola has since expanded the approach to four other countries in the region - the Philippines, China, Malaysia and Australia - bringing e-learning opportunities and resources to tens of thousands of young people and their communities [45].

To consider the gender issues in development of creativity and digital skills, special attention should be paid to the women students. For researchers and educators, more efforts are required such as to encourage confidence of using technologies by dealing with the anxiety, to shape creative learning environment for express ideas equality with boys, to increase number of women students in learning internet technologies, and to provide more opportuni- 
ties of accessing to Internet and this calls for more concerns of creativity among women students in developing contexts and more work on staff development in relation to women issues in learning in digital age in the future.

\section{REFERENCES}

[1] GITR, "The Global Information Technology Report 2010- ICT for Sustainability," 2010.

[2] A. Barak and Y. Sadovsky, "Internet use and personal empowerment of hearing-impaired adolescents," Comput Hum Behav, vol. 24, no. 5, pp. 1802-1815, Sep. 2008. http://dx.doi.org/10.1016/ j.chb.2008.02.007

[3] C.-C. Tsai, S. S. J. Lin, and M.-J. Tsai, "Developing an Internet Attitude Scale for High School Students.," Comput. Educ., vol. 37, no. 1, pp. 41-51, 2001. http://dx.doi.org/10.1016/S03601315(01)00033-1

[4] D. Gauntlett, "Making is connecting: the social meaning of creativity, from DIY and knitting to YouTube and Web 2.0", Polity, Cambridge, UK, 2011.

[5] A. Craft, B. Jeffrey and M. Leibling, "Creativity in education" Continuum International Publishing Group, London, 2001.

[6] T. M. Amabile, "Creativity in context: update to the social psychology of creativity", Westview Press, United States, 1996.

[7] J. P. Guilford, "Creativity". American Psychologist, 5, 1950, pp. 444-454. http://dx.doi.org/10.1037/h0063487

[8] R. J. Sternberg, “Creativity or creativities?" International Journal of Human-Computer Studies, vol. 63, 2005, pp. 370-382. http://dx.doi.org/10.1016/j.ijhcs.2005.04.003

[9] J. P. Sternberg, "Handbook of creativity", Cambridge University Press, New York, 1999.

[10] M. Csikszentmihalyi, "Society, culture, and person: a system view of creativity," In The nature of creativity. R. J. Sternberg Ed., New York: Cambridge University Press, 1988, pp. 325-329.

[11] T. M. Amabile, "Growing up creative: nurturing a lifetime of creativity". Crown, New York, 1989.

[12] C. Zhou and L. Luo, L, "Group creativity in learning context: understanding in a social-cultural framework and methodology," Creative Education, vol. 3, no. 4, pp. 392-399.

[13] B. A. Nijstad and P. B. Paulus. "Group creativity: common themes and future directions". In Group creativity: innovation through collaboration, Paulus, P. B Eds, Oxford University Press, New York, 2003, pp. 326-346. http://dx.doi.org/10.1093/acprof:oso/978 $\underline{0195147308.003 .0015}$

[14] S. Moran and V. John-Steiner, "How collaboration in creative work impacts identity and motivation". In Collaborative creativity, contemporary perspectives, D. Miell and K. Littleton Eds. Free Associate Books, London, 2004, pp.11-25.

[15] G. Pahl, W. Beitz, J. Feldhusen and K. H. Grote, "Engineering design: a systematic approach (The 3rd edition)", Springer, London, 2007. http://dx.doi.org/10.1007/978-1-84628-319-2

[16] S. Paavola, L. Lipponen and K. Hakkarainen, "Models of innovative knowledge communities and three metaphors of learning". Review of Educational Research, vol.74, 2004, pp. 557-576. http://dx.doi.org/10.3102/00346543074004557

[17] C. Bereiter and M. Scardamalia, "Surpassing ourselves: an inquiry into the nature and implications of expertise," Open Court, Chicago, 1993.

[18] S. O' Hear and Sefton-Green, "Creative 'communities': how technology mediates social worlds," In Collaborative creativity, contemporary perspectives, D. Miell and K. Littleton Eds, Free Associate Books, London, pp. 113-125.

[19] M. Yu, C. Zhou and W. Xing, "Change towards creative society: a developed knowledge model for IT in learning". In Frontier and Future Development of Information Technology in Medicine and Education, Lecture Notes in Electrical Engineering: ITME 2013. S. Li, Q. Jin, X. Jiang and J. H. Park, Eds. Springer, vol. 269, 2014, pp. 3373-3377. http://dx.doi.org/10.1007/978-94-007-7618$\underline{0437}$

[20] R. B. Kozma, "The Technological, Economic, and Social Contexts for Educational ICT Policy," in Transforming Education The Power of ICT Policies, UNESCO, 2011.
[21] P. Schumacher and J. Morahan-Martin, "Gender, Internet and computer attitudes and experiences," Comput. Hum. Behav., vol. 17, no. 1, pp. 95-110, Jan. 2001. http://dx.doi.org/10.1016/S0747$\underline{5632(00) 00032-7}$

[22] A. Barak and J. Suler, "Reflections on the psychology and social science of cyberspace.," in Psychological aspects of cyberspace: Theory, research, applications, A. Barak (Ed.)., Cambridge, UK: Cambridge University Press., 2008, pp. 1-12. http://dx.doi.org/10.1017/CBO9780511813740.002

[23] A. Durndell and Z. Haag, "Computer self efficacy, computer anxiety, attitudes towards the Internet and reported experience with the Internet, by gender, in an East European sample," Comput. Hum. Behav., vol. 18, 2002.

[24] J. R. Hill, D. Wiley, L. M. Nelson, and S. Han, "Exploring Research on Internet-Based Learning: From Infrastructure to Interactions," in Handbook of Research on Educational Communications and Technology, Mahwah, NJ: Lawrence Erlbaum Associates, 2004, pp. 433-460.

[25] Y. Amichai-Hamburger, "Internet and personality," Comput. Hum. Behav., vol. 18, no. 1, pp. 1-10, Jan. 2002. http://dx.doi.org/10.1016/S0747-5632(01)00034-6

[26] E. W. Nwagwu, J. Adekannbi, and O. Bello, "Factors influencing use of the internet: A questionnaire survey of the students of University of Ibadan, Nigeria," Electron. Libr., vol. 27, no. 4, pp. 718-734, Jul. 2009. http://dx.doi.org/10.1108/02640470910 979651

[27] R. Walton, J. Yaaqoubi, and B. Kolko, "What's It For? Expectations of Internet Value and Usefulness in Central Asia," Inf. Technol. Int. Dev., vol. 8, no. 3, pp. pp. 69-84, Oct. 2012.

[28] ITU, "Measuring the Information Society 2012," International Telecommunication Union, Geneva, Switzerland, 2012.

[29] ITU, "The World in. 2013 ICT Facts and Figures," ITU Telecommunication Development Bureau, 2013.

[30] M. Warschauer, "Reconceptualizing the Digital Divide," First Monday, vol. 7, no. 7, 2002. http://dx.doi.org/10.5210/fm.v7i7.967

[31] A. van Deursen and J. van Dijk, "Using the Internet: Skill related problems in users' online behavior," Interact. Comput., vol. 21, no. 5-6, pp. 393-402, 2009. http://dx.doi.org/10.1016/ j.intcom.2009.06.005

[32] C. Zhou, A. Purushothaman and N. Rongbutsri, "Facilitate sustainability of education by Problem-Based Learning (PBL) and Information and Communication Technology (ICT), " International Journal of Emerging Technologies in Learning, vol 8, no. 6, 2013, pp. 50-54. http://dx.doi.org/10.3991/ijet.v8i6.3146

[33] A. van Deursen and J. van Dijk, "Measuring Internet Skills," Int. J. Hum.-Comput. Interact., vol. 26, no. 10, pp. 891-916, Sep. 2010. http://dx.doi.org/10.1080/10447318.2010.496338

[34] E. Hargittai, "Second-Level Digital Divide: Differences in People's Online Skills," First Monday, vol. 7, no. 4, 2002. http://dx.doi.org/10.5210/fm.v7i4.942

[35] E. Hargittai, "The Digital Divide and What To Do About It," in New Economy Handbook, D.C. Jones., D. C. Jones, Ed. San Diego, CA: Academic Press, 2003, pp. 822-841.

[36] M.-J. Tsai and C.-C. Tsai, "Information searching strategies in web-based science learning: the role of internet self-efficacy," Innov. Educ. Teach. Int., vol. 40, no. 1, pp. 43-50, Jan. 2003. http://dx.doi.org/10.1080/1355800032000038822

[37] N. Hafkin, "Gender Issues in ICT Policy in Developing Countries: An Overview," Division for the Advancement of Women (DAW) - United Nations, Seoul, Republic of Korea, Expert Group Meeting on "Information and communication technologies and their impact on and use as an instrument for the advancement and empowerment of women," Oct. 2002.

[38] S. Huyer and M. Carr, "Information and Communication Technologies: A Priority for Women," Gend. Technol. Dev., vol. 6, no. 1, pp. 85-100, Mar. 2002. http://dx.doi.org/10.1177/09718524 0200600105

[39] A. Purushothaman, "Empowering Women Through Learning To Use The Internet - An Ethnographic Action Research Project To Address The Second Order Digital Divide," Aalborg University, Denmark, Denmark, 2013.

[40] J. Baer, "Gender differences in the effects of anticipated evaluation on creativity". Creativity Research Journal, vol. 
10, 1997, pp. 25-31. http://dx.doi.org/10.1207/s1532 6934crj1001_3

[41] R. M. Felder, G. Felder, M. Mauney, J. R. Hamrin and E, J, Dietz, "A longitudinal study of engineering student performance and retention. III. Gender differences in student performance and attitudes". Journal of Engineering Education, vol. 84, 1995, pp.151-163. http://dx.doi.org/10.1002/ j.2168-9830.1995.tb00162.x

[42] K. E. Weisman, "Prologue: women's environmental rights: a manifesto", In Gender space architecture: an interdisciplinary introduction, J. Rendell, B.Penner, and L.Borden, Eds. Routledge, London, pp. 170, 2000.

[43] J. H. Raat and V. de Marc, "What do 13-year old students think about technology? The conception of and the attitude towards technology of 13-year old girls and boys". Eindhoven University of Technology, Netherlands, 1985.

[44] C. Zhou, "Group creativity development in engineering education in Problem and Project-Based Learning(PBL) environment," Ph.D. thesis, Aalborg University, Denmark.
[45] F. Wang and C. Zhou, "A theoretical study on development of Information and Communication Technology (ICT)supported education systems". In The Proceedings of 2013 10th International Conference on Fuzzy Systems and Knowledge Discovery (FSKD). J. Chen, X. Wang, L. Wang, J. Sun and X. Meng Eds., IEEE Press, Red Hook, NY, 2013, pp. 1080-1084. http://dx.doi.org/10.1109/ fskd.2013.6816357

\section{AUTHORS}

C. Zhou is with the Department of Learning and Philosophy, Aalborg University, 9000 Aalborg, Denmark (email: chunfang@, learning.aau.dk).

A. Purushothaman is with the Department of Psychology and Communication, Aalborg University, 9000 Aalborg, Denmark (e-mail: aparna@hum.aau.dk)

Submitted 07 November 2014. Published as resubmitted by the authors 11 May 2015. 